(C) [2009] IEEE. Reprinted, with permission, from Zhan, Yuedong; Wang, Hua; Zhu, Jianguo; Guo, Youguang; Xu, Wei. 2009, 'Intelligent Comprehensive Control and Monitor of Proton Exchange Membrane Fuel Cell for Hybrid UPS System', Proceedings of the 4th IEEE Conference on Industrial Electronics and Applications, pp. 3107-3112. This material is posted here with permission of the IEEE. Such permission of the IEEE does not in any way imply IEEE endorsement of any of the University of Technology, Sydney's products or services. Internal or personal use of this material is permitted. However, permission to reprint/republish this material for advertising or promotional purposes or for creating new collective works for resale or redistribution must be obtained from the IEEE by writing to pubspermissions@ieee.org. By choosing to view this document, you agree to all provisions of the copyright laws protecting it. 


\section{Intelligent Comprehensive Control and Monitor of Proton Exchange Membrane Fuel Cell for Hybrid UPS System}

\author{
Yuedong Zhan, Hua Wang \\ Department of Automation \\ Kunming University of Science and Technology \\ Kunming, China \\ ydzhan@163.com,wanghua65@163.com
}

\author{
Wei Xu, Jianguo Zhu, Youguang Guo \\ Faculty of Engineering \\ University of Technology, Sydney \\ Sydney, Australia \\ joe@eng.uts.edu.au, youguang@eng.uts.edu.au
}

\begin{abstract}
This paper, to improve the performance of a Proton Exchange Membrane fuel cell (PEMFC) stack, avoid the hydrogen and oxygen/air starvation of electrochemical reaction and the performance deterioration of the stack, prevent the dehydration and drying of the membrane, keep the water content in the membrane, heighten the utilization of the gases, and track the output power of a hybrid uninterruptible power supply (UPS) system with backup PEMFC and battery power sources, conducts research in the dynamic model, the on-line parameters monitoring of PEMFC, such as the resistance in the PEMFC stack using the current interrupt method and the performance improvement of the PEMFC employing an intelligent comprehensive control strategy of the operation parameters, such as operating temperature, pressures and mass flows of hydrogen and air, the output current and voltage for the PEMFC stack, the power supply switching between PEMFC and battery. The intelligent comprehensive control and monitor method is proposed and applied to the PEMFC generating system employed for the power source of UPS. The experimental results show that the proposal method can effectively monitor and control the pressures of the inlet hydrogen and the operating temperature of the stack, automatically switch the power supply between PEMFC and battery, efficaciously prevent the destroy of the stack when the load changes sharply, the hydrogen is purged and the output current is interrupted regularly, and reasonably improve the performance of the PEMFC through the water balance and thermal management, and real-time realize the tracking for the changes of the output power and the distribution of the mass flow rates of hydrogen and air.
\end{abstract}

key words-proton exchange membrane fuel cell (PEMFC); dynamic model; condition monitoring; intelligent comprehensive controller component; uninterruptible power supply (UPS)

\section{INTRODUCTION}

As the applications of backup power source for a hybrid Uninterruptible Power Supply (UPS) system, the on-line monitor and efficient control of the polymer electrolyte membrane fuel cell (PEMFC) are necessary during the normal working of PEMFC stack when the operating conditions are varying and due to an operation with alternating loads. The power response of the stack depends mainly on the interaction of the stack itself and the necessary peripheral components like hydrogen and air supply, mass flows, temperature and pressure control, heat and water management. To provide the supply of enough power to the external load, the hybrid UPS system employing the PEMFC as the main power source keeps adopting the battery or supercapacitor as auxiliary power source for protecting the PEMFC, keeping the water content balance, preventing excessive use and the reactants starvation of the PEMFC and feeding power smoothly to the external load. Hence, the control and monitor objectives for an UPS backup power supply are to maintain efficiency and to avoid degradation by guaranteeing appropriate temperature, mass flows and partial pressures of the reactants across the electrodes $[1,2]$.

In the control aspects of PEMFC, Pukrushpan et al. [3] focused on three major control subsystems: fuel/air supply, water management and heat management in fuel cell systems. Using feedback and feedforward control, they maintained an excess oxygen ratio and reported the net system power (after subtracting the extra power required for maintaining the excess oxygen ratio and overcoming parasitic losses from the output power) obtained from the fuel cell. Danzer et al. [4] proposed a model-based control structure that comprised a multivariable control of the cathode pressure and the excess ratio of oxygen using the mass flow controller (MFC) and the outlet throttle as actuators. For both controlled variables, appropriate desired values can be specified independently. Moreover, a tracking observer is employed to estimate this pressure using the measured air pressure at the outlet throttle. Thereby, the observer enabled the control system to detect both temporary shortages of oxygen and peak pressures at the cathode and to counteract accordingly in order to avoid oxygen starvation. Vahidi et al. [5] focused on the starvation problem in a hybrid system, where a fuel cell was coupled with a power source that responded quickly through the use of a supercapacitor. They used a model predictive control strategy to avoid starvation and simultaneously match an arbitrary level of current demand.

In the monitoring and failure diagnosis aspects of PEMFC, Hissel et al. [6] presented a fuzzy diagnosis on a fuel cell power generator implemented in a vehicle. The proposed methodology took only into account at the present time two types of faults (accumulation of water/nitrogen in the anode compartment and drying of the membrane). Nevertheless, the 
same kind of methodology could be applied for a greater number of considered faults. Xue et al. [7] proposed a modelbased condition monitoring scheme that employed the Hotelling $\mathrm{T}^{2}$ statistical analysis for fault detection of PEMFC. The basic idea was to compare the fuel cell output voltage measurement with model prediction under the same operating conditions. Riascos et al. [8] developed an on-line fault diagnostic system for PEMFC by applying Bayesian networks, which qualify and quantify the cause-effect relationship among the variables of the process.

In this paper, a single-phase high frequency 300W UPS with a PEMFC/battery hybrid power source has been developed, which can be used in the industries. Fig. 1 schematically illustrates the structure of the hybrid UPS system with a backup PEMFC generating system and battery, which consists of AC/DC rectifier, DC/DC converter, DC/AC inverter, and AC/DC recharger, and their data-acquisition, monitor and control units. The UPS supplies the linear and nonlinear loads with the required uninterruptible AC power. The PEMFC stack operates on hydrogen and air. Because of the slow start-up of the PEMFC stack, which may take a few seconds, the small capacity battery is required for UPS applications. The hybrid UPS system designed has a lot of advantages, such as low cost, weight, size, and so on.

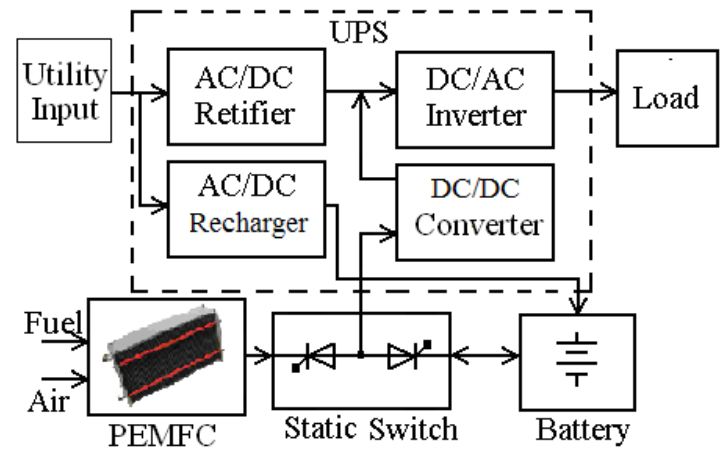

Figure 1. Single-phase high frequency hybrid UPS system with backup PEMFC and battery

\section{DYNAMIC MODEL OF PEMFC}

\section{A. Polarization Curve Model}

Based on analyzing the dynamic model of the PEMFC, including dynamic gas transport model, the manifold model, the thermal model, and the performance curve model in details, a dynamic model was developed [9]. Because of the activation loss voltage $V_{\text {actLOSS, }}$ Ohmic loss voltage $V_{\text {OhmicLOSS, }}$ concentration loss voltage $V_{\text {concLoss }}$ and leakage loss voltage (internal current) $V_{\text {leakLoss }}$ for PEMFC, the mathematical polarization curve model of the PEMFC stack will be:

$$
\begin{aligned}
V_{\text {stack }} & =V_{\text {reversible }}-V_{\text {actLOSS }}-V_{\text {OhmicLOSS }}-V_{\text {contLOSS }}-V_{\text {leakLOSs }} \\
& =V_{\text {reservible }}-N_{\text {CELL }}\left\{\frac{R T}{\alpha F} \ln \left(\frac{i+i_{n}}{i_{0}}\right)+R_{\text {Ohmic }}\left(i+i_{n}\right)+\frac{R T}{n F} \ln \left[\frac{i_{L}}{i_{L}-\left(i+i_{n}\right)}\right]\right\}
\end{aligned}
$$

where $V_{\text {reversible }}$ is the reversible voltage (V); $N_{\text {cell }}$ the number of cells in a PEMFC stack; $\alpha$ is the transfer coefficient; $n$ the number of electrons per molecule of $\mathrm{H}_{2}=2$ electron per molecule; $R$ the universal gas constant (atm/kmol K); $T$ the stack temperature $(\mathrm{K}) ; \quad F$ the Faraday's constant $(\mathrm{C} / \mathrm{mol})$; $R_{\text {Ohmic }}$ the area-normalized resistance, also known as area specific resistance (ARS) of the PEM fuel cell measured ( $\Omega$ $\left.\mathrm{cm}^{2}\right) ; i_{0}$ the exchange current density $\left(\mathrm{mA} / \mathrm{cm}^{2}\right) ; i_{L}$ the limiting current density at which the cell voltage will fall rapidly $\left(\mathrm{A} / \mathrm{cm}^{2}\right) ; i_{n}$ the internal current or parasitic current that is wasted $\left(\mathrm{A} / \mathrm{cm}^{2}\right) ; i$ the PEMFC stack current density $\left(\mathrm{A} / \mathrm{cm}^{2}\right)$.

The reversible voltage at varying temperature and pressure can be expressed as:

$$
\begin{aligned}
V_{\text {reversible }}= & N_{\text {cell }} \times 1.23+\left(4.308 \times 10^{-5}\right) T \times \ln \left[\frac{P_{\mathrm{H}_{2}}\left(P_{\mathrm{O}_{2}}\right)^{\frac{1}{2}}}{P_{\mathrm{H}_{2} \mathrm{O}}}\right] \\
& -N_{\text {cell }} \times\left(8.453 \times 10^{-4}\right)(T-298 . .15)
\end{aligned}
$$

where $P_{i}$ is the partial pressure of species $i\left(\mathrm{H}_{2}, \mathrm{O}_{2} /\right.$ air, and liquid water) (atm), respectively.

According to the conservation of energy, the ideal gas law, the proportional relationship between the gas outlet flow through a valve and the partial pressure, and Faraday's law, $P_{\mathrm{H}_{2}}, P_{\mathrm{O}_{2}}$ and $P_{\mathrm{H}_{2} \mathrm{O}}$ can be reconstructed in the s domain as:

$$
\begin{gathered}
P_{\mathrm{H}_{2}}=\frac{1 / k_{\mathrm{H}_{2}}}{1+\tau_{\mathrm{H}_{2}} \mathrm{~S}}\left(Q_{\mathrm{H}_{2}}^{\text {in }}-2 k_{r} I\right) \\
P_{\mathrm{O}_{2}}=\frac{1 / k_{\mathrm{O}_{2}}}{1+\tau_{\mathrm{O}_{2}} S}\left(Q_{\mathrm{O}_{2}}^{\text {in }}-k_{r} I\right) \\
P_{\mathrm{H}_{2} \mathrm{O}}=\frac{1 / k_{\mathrm{H}_{2} \mathrm{O}}}{1+\tau_{\mathrm{H}_{2} \mathrm{O}} \mathrm{S}}\left(Q_{\mathrm{H}_{2} \mathrm{O}}^{\text {in }}+2 k_{r} I\right)=\frac{1 / k_{\mathrm{H}_{2} \mathrm{O}}}{1+\tau_{\mathrm{H}_{2} \mathrm{O}}}\left(2 k_{r} I\right)
\end{gathered}
$$

where $\tau_{\mathrm{H}_{2}}, \tau_{\mathrm{O}_{2}}$ and $\tau_{\mathrm{H}_{2} \mathrm{O}}$ are the time constant of e hydrogen, oxygen, and water (s); $Q_{\mathrm{H}_{2}}^{\text {in }}, Q_{\mathrm{O}_{2}}^{\text {in }}$ and $Q_{\mathrm{H}_{2} \mathrm{O}}^{\text {in }}$ the inlet flow rates of each species $(\mathrm{kmol} / \mathrm{s}) ; k_{\mathrm{H}_{2}}, k_{\mathrm{O}_{2}}$ and $k_{\mathrm{H}_{2} \mathrm{O}}$ each species valve molar constant ( $\square \mathrm{tm} \mathrm{kmol} / \mathrm{s}$ ); $k_{r}$ the modeling constant ( kmol/ $\square \mathrm{s} \square$.

The inlet pressure of each gas can be calculated as:

$$
\begin{aligned}
P_{\mathrm{H}_{2}}^{\text {in }} & =\frac{1}{1+\tau_{\mathrm{H}_{2} \text { pпеи }}}\left(R_{\mathrm{H}_{2} \text { рпеи }} Q_{\mathrm{H}_{2}}^{\text {in }}+P_{\mathrm{H}_{2}}\right) \\
P_{\mathrm{O}_{2}}^{\text {in }} & =\frac{1}{1+\tau_{\mathrm{O}_{2} \text { pпеи }}}\left(R_{\mathrm{O}_{2} \text { pпеи }} Q_{\mathrm{O}_{2}}^{\text {in }}+P_{\mathrm{O}_{2}}\right)
\end{aligned}
$$

where $P_{H_{2}}^{\text {in }}$ and $P_{\mathrm{O}_{2}}^{\text {in }}$ are the inlet manifold or a pipe pressure of hydrogen and oxygen (atm); $R_{H_{2} \text { pneu }}$ and $R_{\mathrm{O}_{2} \text { pneu }}$ the pneumatic resistance of the hydrogen and oxygen manifold $(\Omega)$; 
$C_{\mathrm{H}_{2} \text { pneu }}$ and $C_{\mathrm{O}_{2} \text { pneu }}$ the pneumatic capacitance of the hydrogen and oxygen manifold (F); $\tau_{H_{2} \text { pneu }}$ and $\tau_{\mathrm{O}_{2} \text { pneu }}$ the pneumatic time constant the hydrogen and oxygen manifold (s).

\section{B. Thermal Model}

According to the Fourier's law of Conduction, when involving internal heat generation due to electrical resistance, the rate of heat transferred by conduction in the one-dimension is expressed by [10]:

$$
\frac{d^{2} T}{d x^{2}}+\frac{q_{\text {int }}}{k A}=0
$$

where $k$ is the thermal conductivity $\left(\mathrm{W} / \mathrm{m}^{-1} \mathrm{~K}^{-1}\right)$; $A$ the finite cross-sectional area $\left(\mathrm{m}^{2}\right) ; q_{\text {int }}$ the rate of heat generation per unit volume $(\mathrm{W})$.

\section{Dynamic Model of PEMFC}

As mentioned above, a detailed dynamic model of the PEMFC is shown in Fig. 2. This model is based on the relationship between output voltage and the partial pressures of hydrogen, oxygen/air, temperature of the stack and water.

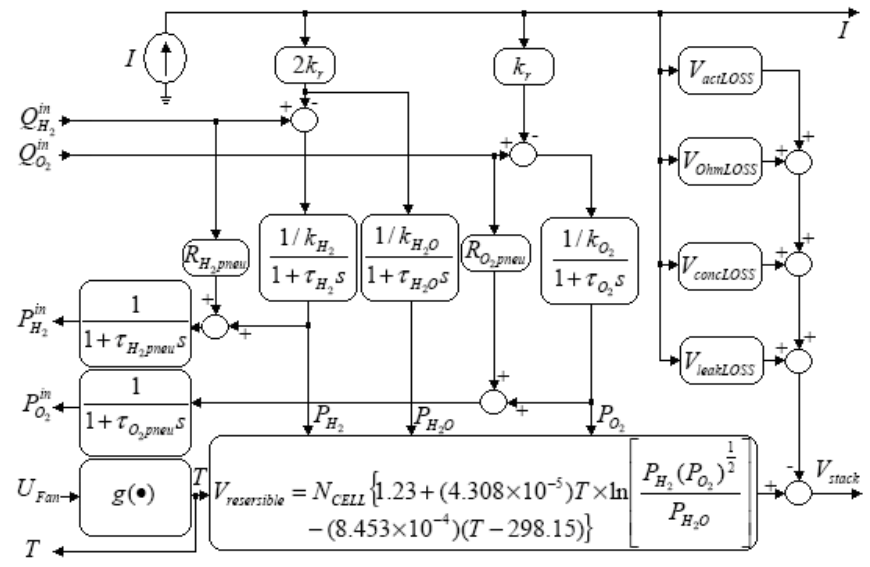

Figure 2. PEMFC dynamic model

\section{INTELLIGENT COMPREHENSIVE MONITOR AND CONTROL}

A lot of work has been investigated on the PEMFC by various researchers and some methods have been presented to control the key PEMFC parameters for improving the water balance and thermal management and performance of PEMFC [11]. Fig. 3 shows a block diagram of a PEMFC powered system as the power source of hybrid UPS system, which consists of a 300W 63-cell self-humidified air-cooling stack, a monitor system of water content, temperature, pressure, mass flow rates, current and voltage of PEMFC stack, and five types of controllers: power tracking controller, hydrogen pressure controller, hydrogen mass flow controllers (HMFC), air supply and thermal controller, and power switching controller. In the Fig. 3, M is a multiplier, which is applied on-line to calculate the output power of the PEMFC; $\mathrm{SCR}_{1}, \mathrm{SCR}_{2}$ are the SiliconControlled Rectifiers (SCR), which are used to switch the power sources between PEMFC and battery for UPS when the load increases sharply, the current interrupts for measuring the resistance of PEMFC, and the utility grid power and PEMFC fail.

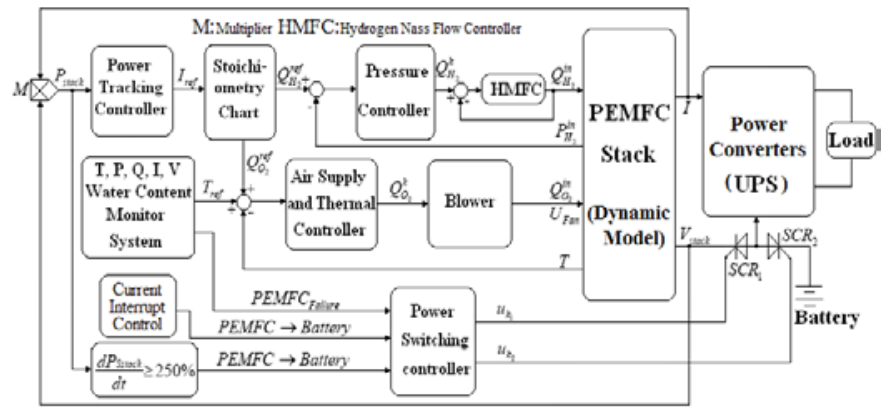

Figure 3. Control and monitor diagram of a PEMFC powered system for UPS applications

\section{A. Monitor System}

In this paper, a monitor system has been designed to analysis the operation of PEMFC in fault conditions firstly, then to decide the power sources switching from PEMFC to battery for hybrid UPS system. The monitor system is of the sensor function, the control function and the power sources switching function. The sensor function allows monitoring the current, voltage, temperature, and pressure of PEMFC stack, the mass flow rate and relative humidity of hydrogen. The control function allows the speed adjustment of the three blowers and the temperature control of the stack combining with the air supply and thermal controller. The power sources switching function allows the power switching controller to supply the power source from PEMFC to battery when PEMFC stack fails.

In order to monitor the water balance, the open-voltage and current-voltage performance of PEMFC stack, and diagnose the operating processes taking place in the PEMFC, the measurement of the polarization curve and the current interrupt can be used to determine if there is anything wrong with the PEMFC. The polarization curve can be obtained using the measurement of the current and voltage values of the stack online. The polarization curve provides useful but sufficient information about the performance of the PEMFC. A quick measurement of the stack resistance may provide more information about the PENFC performance. Because both flooding and drying of a cell would result in a loss of voltage, that is, the stack resistance value will be changed. Therefore, the water balance can be reflected by the stack resistance.

One of the methods to measure the resistance in the PEMFC stack is the current interrupt method. In this method, the current is interrupted for a very short period, which is determined by the current value of the stack, and resulting voltage gain is observed and calculated. The difference between the stack voltage before and after the current interrupt, divided by the current, is the stack resistance $R_{\text {Ohmic }}$, as shown in Fig. 4, which is expressed by below equation. When the current interrupts, the power switch controller can control the power source of UPS to switch from PEMFC to battery.

$$
R_{\text {Ohmic }}=\frac{\Delta V_{R}}{I}
$$




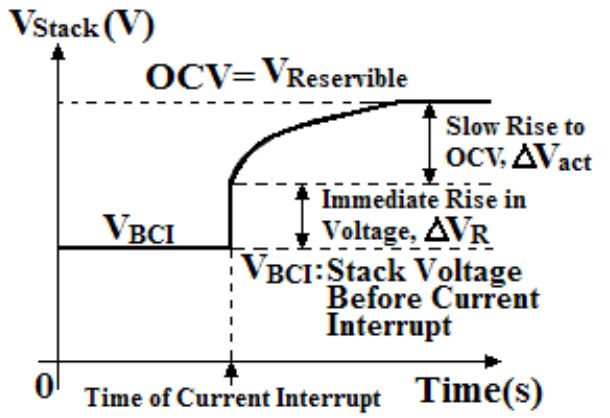

Figure 4. Stack voltage after current interrupt

\section{B. Intelligent Comprehensive Control}

\section{1) Power traching controller}

According to the real-time current and voltage measurements of PEMFC stack, the power density (ranging from 12 to $330 \mathrm{~W}$ ) can be firstly calculated. The output power of the fuel cell stack can be calculated by the expression:

$$
P_{\text {stack }}=V_{\text {stack }} I
$$

where $P_{\text {stack }}$ is the output power of the stack $(\mathrm{W}) ; V_{\text {stack }}$ the output voltage of the stack (V); I the output current of the stack (A).

Based on the load at that time, a power tracking controller is designed to continuously distribute the current or real-time power by using the setup value of the reference mass flow $Q^{r e f}{ }_{2}$ and $Q^{r e f}{ }_{O 2}$ of hydrogen and air and according to the stoichiometry radios of PEMFC. The mass flow rates of hydrogen and air for the stack can be calculated as follows.

\section{2) Fuzzy mass flow controller of hydrogen}

The fuzzy-PI controller input variable are the mass flow error $e(k)$, and the change of error $c(k)$ of hydrogen. The output variables of the controller are the optimal $P$ and $I$ gains of a subsequent PI controller device, one of them gives the proportional part $K$ as a function of $e(k)$ and $c(k)$, and the other gives the increment $\Delta T$, which is then integrated to provide the integral term $T$ of the PI controller. There are the seven fuzzy subsets: positive big (PB), positive medium (PM), positive small (PS), zero (ZE), negative small (NS), negative medium (NM), and negative big (NB), have been selected for the input and output variables $e(k), c(k), K$ and $T$. The fuzzy control rules are obtained from the behaviour analysis of the PEMFC system. Because the rule-base represents the intelligence of the controller, the formulations must be carefully considered. Correct use of control laws according to the operating conditions can greatly improve the system stability. A fast response with a small overshoot for the PEMFC system can be achieved with proper handling of the proportional and integral part. It is the cause that the fuzzy-PI controller is more advantageous than a standard PI controller [12].

\section{3) Air supply and thermal controller}

The PEMFC belongs to the low temperature stack $\left(<100^{\circ} \mathrm{C}\right)$ in the fuel cell family, but its operating temperature is still higher than the ambient temperature and should be maintained within an appropriate range. The operating temperature is selected according to the characteristics of the PEMFC offered by the manufactures. In this paper, the best operating temperature employing the PEMFC is at $50 \sim 60^{\circ} \mathrm{C}$ (the max stack temperature is $65^{\circ} \mathrm{C}$ ) according to the manual.

As mentioned above, the thermal model is a nonlinear relationship. In order to keep the water balance in the stack and obtain the control results very well, in practice, when the stack temperature is less than $50^{\circ} \mathrm{C}$, the thermal controller implements the basic velocity adding digital proportional and integral (PI) control strategy. When the stack temperature is more than $50^{\circ} \mathrm{C}$, an adaptive fuzzy control strategy is employed as the air supply and air-cooling control.

Using the model identification method of control theory, such as fuzzy identification, artificial network identification, adaptive fuzzy network identification and other methods, the identification model can be expressed by below nonlinear differential equation.

$$
T(k)=g\left(T(k-1), U_{\text {Fan }}(k-1), T_{\text {Air }}(k-1)\right)
$$

The air supply and thermal control rules are:

Rule1: If $T$ is less than $50^{\circ} \mathrm{C}$, then

$$
Q_{O_{2}}^{k}=K_{P}\left(T_{r e f}-T(t)\right)+K_{I} \int\left(T_{r e f}-T(t)\right) d t
$$

Rule2: If $T$ is more than $50^{\circ} \mathrm{C}$ and less than $60^{\circ} \mathrm{C}$, then

$$
Q_{\mathrm{O}_{2}}^{k}=\text { adaptive fuzzy control; }
$$

Rule3: If $P_{\text {stack }}$ is over $330 \mathrm{~W}$ or $T_{\text {stack }}$ is over $65^{\circ} \mathrm{C}$, then the PEMFC is shut down.

\section{4) Pressure controller}

An increase in PEMFC operating pressure results in higher cell voltage according to the Nernst equation and the increase in exchange current density due to increased concentration of reactant gases in the PEMFC electrodes. According to the demands of the PEMFC, this paper adopts the steady pressure equipment to control the reactant gas pressure. The system can also control the hydrogen pressure about $34.5 \mathrm{kPa}$ (5 psi). Three fans are used to feed air and cool the stack.

The mode of hydrogen supply designed is a dead-end mode, however, hydrogen has to be periodically purged, because of accumulation of inert and water. When hydrogen is purged, the pressure will be changed. In this paper, in order to prevent the pressure change and protect the stack, a simple method is used. When hydrogen is purged, the power switching controller can control the power source from PEMFC to battery.

The control method of the (PID) is used in the pressure controller, that is, the hydrogen output controlling variable is:

$Q_{H_{2}}^{k}=K_{P} e_{H_{2}}(k T)+\frac{T}{T_{I}} \sum_{j}^{k} e(j T)+\frac{T_{D}}{T}\left[e_{H_{2}}(k T)-e_{H_{2}}(k T-T)\right]$

here, $\quad e_{H_{2}}(k T)=Q_{H_{2}}^{r e f}(k T)-P_{H_{2}}^{\text {in }}(k T)$

where $\mathrm{T}$ is the sampling period (s).

5) Power switching controller 
The complex electrode phenomenon exists in the PEMFC called the charge double layer. This acts as a capacitance and gives the PEMFC stack a smooth dynamic voltage output. When the load on the PEMFC stack changes, the voltage output has an initial Ohmic voltage loss from the resistance of the PEMFC stack and then it slowly moves to the new voltage. When the load is suddenly increased, the HMFC and blowers may not be able to provide sufficient hydrogen and air to sustain the operation under the new load condition. This can lead to temporary hydrogen and air starvation, thereby causing irreversible damage to the stack. To avoid the hydrogen and air starvation, in this paper, a power switching controller is simply designed, which can control the power sources of hybrid UPS system to switch between PEMFC and battery according to the change rate of the power of the PEMFC stack. Transient issues associated with temporary hydrogen and air starvation can be avoided by supplying the power from the battery and slowing down the current drawn from the PEMFC through a change rate limiter of the power output. On the other hand, when the monitor system diagnoses the failure of PEMFC, the power switching controller can switch the power sources supplying UPS from PEMFC to battery.

The intelligent control rules are as follows. As shown in Fig. $3, u_{k_{1}}=1$ means that the $\mathrm{SCR}_{1}$ turns on; $u_{k_{1}}=0$ means that the $\mathrm{SCR}_{1}$ turns off; $u_{k_{2}}=0$ means that $\mathrm{SCR}_{2}$ turns off; $u_{k_{2}}=1$ means that the $\mathrm{SCR}_{2}$ turns on.

Rule1: If the change of load is less than $250 \%$, then $u_{k_{1}}=1$ and $u_{k_{2}}=0$;

Rule2: If the change of load is more than $250 \%$, then $u_{k_{1}}=0$ and $u_{k_{2}}=1$;

Rule3: If the current interrupt is executed, then $u_{k_{1}}=0$ and $u_{k_{2}}=1$;

Rule4: If the hydrogen is purged, then $u_{k_{1}}=0$ and $u_{k_{2}}=1$;

Rule5: If the PEMFC is failure, then $u_{k_{1}}=0$ and $u_{k_{2}}=1$.

\section{EXPERIMENTAL SETUP AND RESULTS}

The experimental setup consists of a UPS system, PEMFC generating system, lead-acid batteries and a data-acquisition system. The UPS system with backup PEMFC and battery provides the AC power source and controls the linear loads (e.g. lamp box) and nonlinear loads (i.e. PC), while the dataacquisition system measures and records the required information. All physical parameters such as currents and voltages of the UPS, PEMFC stack and battery, gas mass flow of the reactants, pressure drop in the flow fields, relative humidity and temperatures of air and hydrogen are recorded with the data-acquisition system.

Experimental study has been conducted on the designed UPS with backup PEMFC and battery. The proposed intelligent comprehensive monitor and control strategies have been implemented in the PEMFC generating system. Based on the intelligent comprehensive controllers, the output voltage and current values of the PEMFC stack are easily controlled according to the load changes of the UPS, as shown in Fig. 5.

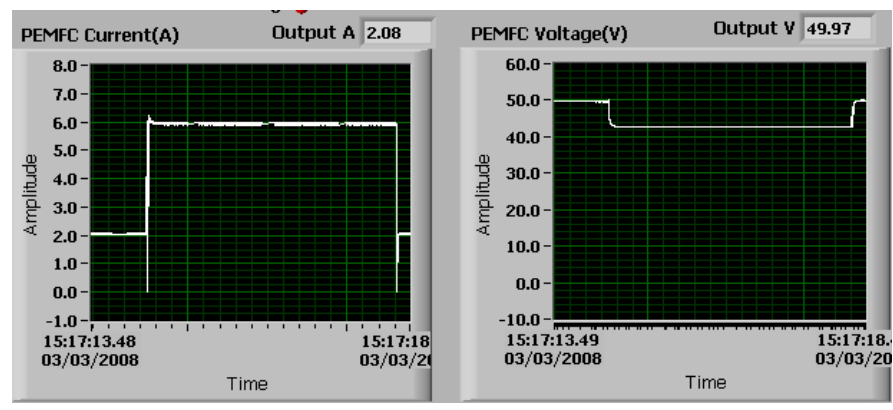

Figure 5. Current and voltage of PEMFC when UPS load changes

With the increase of the load, the temperature of PEMFC stack will go up. Because of the adjusting of thermal controller, the temperature of the stack will keep in the range of the 50 60 ${ }^{\circ} \mathrm{C}$, as shown in Figs. 6 and 7. In general, higher operating temperature is desirable due to decreased mass transport limitations and increased electrochemical reaction rates; at the same time, high temperatures may lead to increase mass transport losses due to the increase of water vapour. Therefore, in this experimental, the stack temperature is controlled whin $50 \sim 60^{\circ} \mathrm{C}$, in order to keep the water balance and reduce the effect of the internal resistance or Ohmic losses.

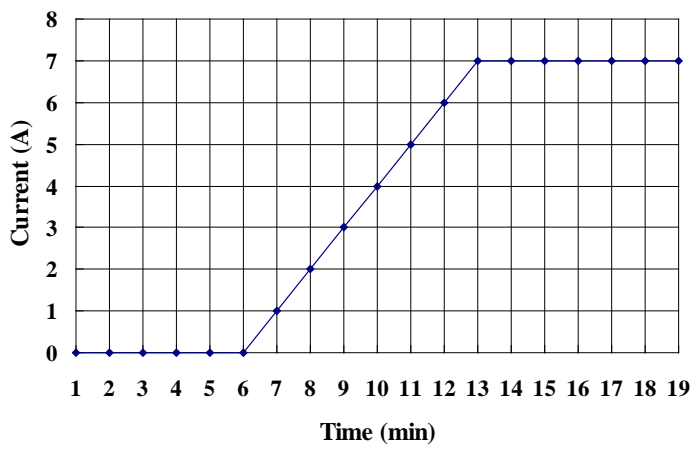

Figure 6. Current char when UPS runs with load changing

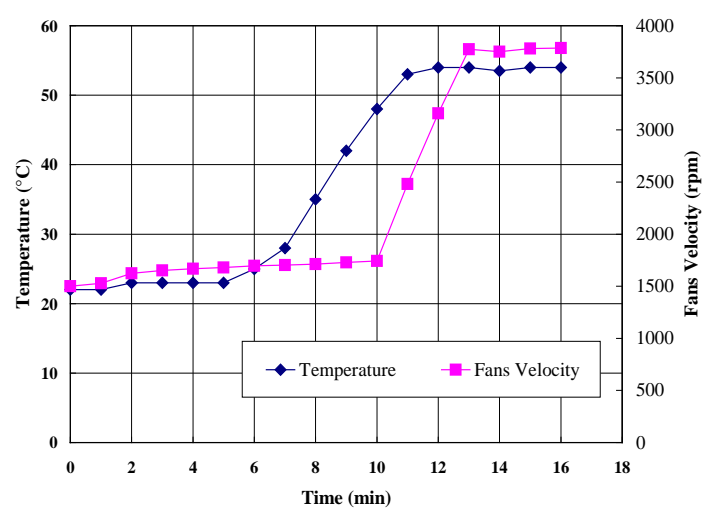

Figure 7. Stack temperature and fans velocity charts when UPS runs with load changing 
The experimental results also reveal that when the external load has a sudden change, however, the hydrogen cannot be fed fast enough to the PEMFC stack. When the load of the UPS suddenly changes, for example, from $60 \mathrm{~W}$ to $210 \mathrm{~W}$, the output voltage of the PEMFC stack goes down quickly and makes the UPS shut down, therefore, this result will make hydrogen and air be starvation and may spoil the PEMFC stack. To supply enough power to the external load and protect the PEMFC stack, the hybrid UPS system keeps adopting the lead-acid battery for protecting the PEMFC in order to prevent excessive use of the PEMFC and to feed power smoothly to the external load. As shown in Fig. 8, the PEMFC stack can supply the UPS with power source for a long time in the normal conditions, when the load of the UPS sharply changes or hydrogen is purged, the power switch controller can switch from PEMFC to battery.

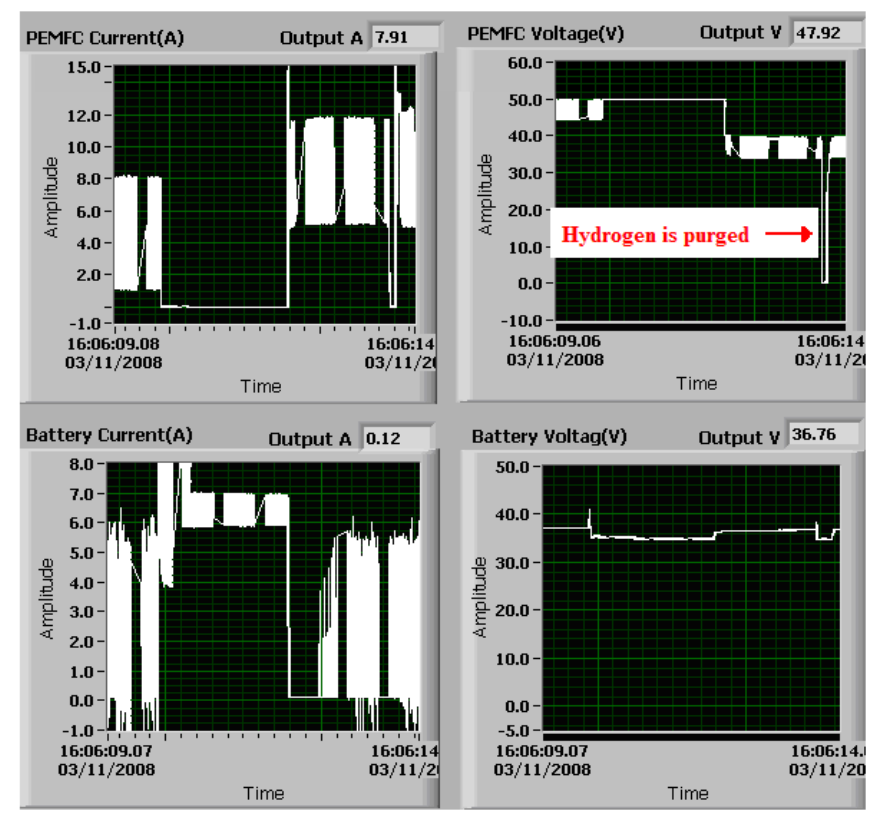

Figure 8. Power supply from PEMFC to battery when the load of UPS changes sharply (over 250\%) and hydrogen is purged

The intelligent comprehensive control performance curve and the conventional PI control performance of PEMFC stack are given in Fig. 9.

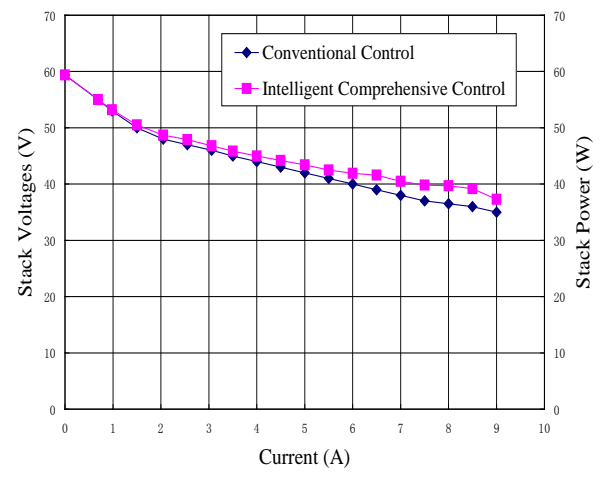

Figure 9. Comparison of performance between intelligent comprehensive control and conventional control

\section{CONCLUSION}

The intelligent comprehensive control and monitor strategy has developed for improving the PEMFC performance at different operational conditions. The monitor system is of the sensor function, the control function and the power sources switching function. The intelligent comprehensive controller has been designed to control the input mass flows and pressures of hydrogen, air mass flows, the stack temperature, and the switching of the power sources between the PEMFC stack and battery. The proposed intelligent comprehensive controller includes the power tacking controller, hydrogen pressure controller, hydrogen mass flows controller, air supply and thermal controller, power switching controller. The designed monitor system and the power switching controller can on-line do the work of the current interrupting for measuring the resistance of PEMFC stack and the hydrogen purging for exhausting the inert gas and water. The experimental results have proved that the proposed control and monitor scheme can work better comparing with the conventional control strategy. A major advantage of the intelligent comprehensive control over the existing conventional control is its capability to further solve the problem of the fuel/air starvation, flooding and drying, performance deterioration for a PEMFC.

\section{REFERENCES}

[1] J. B. Jia, Y. T. Cham, Y. Wang, and Frank Lewis, "The electrical dynamic response study of PEMFC as a backup power supply,” IEEE International Conference on Control and Automation, ThB 1-4, Guangzhou, China, May 30 to June 1, 2007.

[2] Y. P. Yang, F. C. Wang, H. P. Changb, Y. W. Ma, and B. J. Weng, "Low power proton exchange membrane fuel cell system identification and adaptive control," Journal of Power Sources, Vol.164, pp.761-771, 2007.

[3] J.T. Pukrushpan, A.G. Stefannopoulou, H. Peng, "Control of fuel cell breathing,” IEEE Control Systems Magazine, pp.30-46, April 2004.

[4] M. A. Danzer, J. Wilhelm, H. Aschemann, and E. P. Hofer, "Modelbased control of cathode pressure and oxygen excess ratio of a PEM fuel cell system,” Journal of Power Sources, Vol. 176, pp. 515-522, 2008.

[5] A. Vahidi, A. Stefanopolou, H. Peng, "Model predictive control for starvation prevention in a hybrid fuel cell system," in Proceedings of 2004 American Control Conference, Boston, Massachusetts, pp. 834-839, June 30-July 2, 2004.

[6] D. Hissel, M.C. Péra, and J.M. Kauffmann, "Diagnosis of automotive fuel cell power generators," Journal of Power Sources, Vol. 128, pp. 239-246, 2004.

[7] X. Xue, J. Tang, N. Sammes, and Y. Ding, "Model-based condition monitoring of PEM fuel cell using Hotelling $\mathrm{T}^{2}$ control limit,” Journal of Power Sources, Vol. 162, pp. 388-399, 2006.

[8] L. Riascos, M. Simoes, and P. Miyagi, "On-line fault diagnostic system for proton exchange membrane fuel cells,” Journal of Power Sources, Vol. 175, pp. 419-429, 2008.

[9] Y. D. Zhan, J. G. Zhu, Y. G. Guo, H. Wang, "Comprehensive control of proton exchange membrane fuel cell as backup power supply for UPS," in Proceedings of $27^{\text {th }}$ Chinese Control Conference, Kunming, Yunnan, China, pp. 646-651, 16-19 July 2008.

[10] F. Barbir, FEM Fuel Cell: Theory and Practice, Elsevier Academic Press, New York, 2005.

[11] C. Spiegel, Designing and Building Fuel Cell, McGraw Hill Companies, New York, 2007.

[12] Y. D. Zhan, J. G. Zhu, Y. G. Guo, and J. X. Jin, "Control of proton exchange membrane fuel cell based on intelligent", in Proceedings of the $26^{\text {th }}$ Chinese Control Conference, Zhangjiajie, Hunan, China, pp. 20152019, 26-31 July 2007. 
